\title{
АНАЛИЗ ФАКТОРОВ, ФОРМИРУЮЩИХ ПРОГРАММЫ МЕДИА-ПРОДВИЖЕНИЯ РОССИЙСКОГО РОЗНИЧНОГО РИТЕЙЛА
}

\author{
А.С. Дёмин \\ Московский гуманитарный университет
}

\begin{abstract}
Аннотация: В статье анализируются особенности факторов внешней и внутренней среды, влияющих на программы медиа-продвижения российского розничного ритейла. Отмечается, что в ритейле произошел переход к кониепции маркетинга отношений. Делается вывод, что на программы медиа-продвижения особое влияние оказывают экономические, политические $и$ научно-технические факторы.
\end{abstract}

Ключевые слова: медиа-продвижение, розничный ритейл, факторы внешней среды, продвижение

\section{ANALYSIS OF THE FACTORS SHAPING THE MEDIA PROMOTION PROGRAMS OF THE RUSSIAN RETAIL RETAIL}

\author{
A.S. Demin \\ Moscow University for the Humanities
}

\begin{abstract}
The article analyzes the features of the factors of the external and internal environment that affect the programs of media promotion of Russian retail. It is noted that in retail there has been a transition to the concept of relationship marketing. It is concluded that the programs of media promotion are particularly influenced by economic, political, scientific, and technical factors.
\end{abstract}

Keywords: media promotion, retail, environmental factors, promotion

Одним из наиболее приоритетных секторов торговли является рынок розничного ритейла, который начал активно развиваться в конце 1990-х гг. За это время на рынке появилось множество крупных брендов: X5 RetailGroup, «Магнит», «ВкусВилл», «Лента», «Азбука Вкуса», DNS, «М.Видео-Эльдорадо», «Дикси», «Рольф», Widberries, FixPrice, «Спортмастер» и др.

В 2019 г. оборот розничной торговли в Российской Федерации составил 33,532 трлн. рублей (Оборот российского ритейла в 2019 году..., 2020). Рост составил 1,6\% по отношению 2018 г. В структуре оборота удельный вес продуктов составляет 47,9\%, непродовольственных товаров - 52,1\%. При этом по данным Минэкономразвития оборот розничной торговли в 2020 г. снизится на 5,2\%, а в последующие годы темпы роста не будут выше 3,2\% (Оборот российского ритейла в 2020 году..., 2020).

Поэтому для российских торговых сетей особое значение приобретает медиапродвижение, способствующее брендов, донесение уникального предложения и налаживание контакта с аудиторией, что в конечном итоге влияет на рост выручки.

В отечественной научной литературе немного аналитических работ, посвя- 
щенных системному анализу розничной торговли в целом и медиапродвижению в частности.

По мнению Т.В. Евстигнеевой в розничной торговле в настоящее время произошел переход к концепции маркетинга отношений, которая направлена на удержание существующих потребителей, повышение качества обслуживания, формирования потенциальной лояльности потребителей к бренду (Евстигнеева, 2008). В свою очередь О.Г. Гондаренко полагает, что торговые сети свою маркетинговую стратегию строят на основе целевого взаимодействия с клиентами, включающую в себя элементы ценового доминирования (Гондаренко, 2013).

По мнению автора маркетинг в розничной торговле можно рассматривать как комплекс технологий, призванных оказать стимулирующее воздействие на потребителей, а также на контрагентов, торговый персонал, направленных на увеличение объема продаж с одновременным увеличением числа новых покупателей, а также - на увеличение числа повторных покупок.

Однако на формирование программ медиапродвижения торговых сетей влияют определённые факторы внешней и внутренней среды.

Внешняя среда представлена факторами экономического, социально-культурного, демографического и научно-технического характера. Следовательно, внешнюю среду можно определить, как совокупность всех сил и факторов, с которыми торговое предприятие сталкивается в своей повседневной и стратегической деятельности.

Внешние факторы классифицируют по многообразным признакам, но основными из них являются:

- экономические;

- политические;

- демографические;

- научно-технологические;

- природные.

К экономическим факторам, которые влияют на программы медиапродвижения современной торговой компании можно отнести: государственную экономическую политику; состояние национальной экономики (темпы роста); динамику развития рынка и его насыщенность; покупательную способность населения; уровень инфляции и безработицы и т.д.

В розничной торговле динамика развития рынка и его насыщенность, а также покупательская способность населения вынуждает торговые сети всё больше внедрять маркетинговые акции (промо-акции). Так, в период падения платежеспособности населения (в 2017 г. сокращение составило 1,7\%, в 2016 г. - 5,8\%, в 2015 г. - 3,2\%, в 2014 г. - 0,7\% (Реальные доходы россиян в 2019 году..., 2019). Промо-акции стали настоящим инструментом борьбы за покупателя. В 2019 г. их доля в магазинах современных форматов достигала 54\% от общего объема 
транзакций (Мораторий на промо-акции: скидки в магазинах могут запретить..., 2016). В результате торговые сети включают коммуникативные рекламные акции в свои программы медиапродвижения.

Таким образом, рынок приходит к ситуации, когда ритейлеры считают скидки на товары повседневного спроса базовой составляющей ценовой политики, как отмечают эксперты. Промо-акции остаются одним из самых эффективных маркетинговых инструментов в гонке за покупателем.

Политические факторы, влияющие на программы медиапродвижения торговых сетей, представляют собой, прежде всего, направления государственной политики, стабильность законодательных норм в национальной экономике, принципы государственного регулирования экономики, внешнеэкономическую политику государства и т.д. В частности, законодательные и нормативные акты определяют основные правила работы сетевых ретейлеров, а также ненадлежащую рекламу.

Ненадлежащая реклама, которая, имея сильное информационное и психологическое влияние на граждан, может как способствовать эффективному продвижению товаров и услуг, так и опорочить конкурентов, а также ввести потенциальных потребителей в заблуждение по поводу происхождения и свойств производимой продукции или оказываемых услуг.

Учитывая стремительное развитие рекламы и средств ее распространения, был принят Федеральный закон №38-Ф3 «О рекламе», который вступил в силу 1 июля 2006 г. Он представляет собой кодифицированный правовой акт, охватывающий различные виды рекламной деятельности, а также устанавливающий контроль над соблюдением норм и ответственность за их нарушение или ненадлежащее исполнение.

Защита от недобросовестной конкуренции и ненадлежащей рекламы является одной из целей административно-правового регулирования предпринимательских отношений. Например, ФАС России признала неправомерной рекламу ООО «Ив Роше Восток» в 2019 г., запущенную компанией в интернете. Жалобу подала компания ООО «Л'Окситан Рус», т.к. в рекламе конкурента в поисковых системах «Яндекс» и «Google» упоминался её бренд в негативном контексте: «Покупаете косметику L'Occitane? A в Yves Rocher только натуральная косметика и парфюмерия» и т.д. (Ненадлежащая реклама «Ив Роше», 2011).

Основная цель государственного регулирования конкуренции и рекламной деятельности в России - обеспечение баланса публичных и частных интересов, развитие рынков товаров, работ и услуг в эпоху информационного общества на основе соблюдения принципов добросовестной конкуренции.

Демографические факторы определяются такими показателями, как уровень образования людей, уровень безработицы в стране, предпочтения потребителей, старение населения, высокий уровень смертности работоспособного населения, культурный уклад общества, «утечка мозгов» и т.д. 
В настоящее время на программы медиапродвижения особое влияние оказывают научно-технические факторы. С учетом развития цифровой экономики возрастает роль коммуникаций в сети интернет, который, средство коммуникации, неотъемлемой современной. Он учитывает вариантов решений и диалога. Продвижение в интернете включает поисковый маркетинг, контекстную, баннерную рекламу, SMM.

Социальные сети сегодня - мощнейший канал продвижения для розничного бизнеса. Однако, значение социальных сетей в розничной торговле порой недооценивают, отдавая предпочтение традиционным маркетинговым каналам. Так, согласно данным исследовательского центра Mediascope, в 2019 г. самой популярной социальной сетью по-прежнему остается «ВКонтакте» с аудиторией в 38,2 млн пользователей. На втором месте - Instagram (30,6 млн), а на третьем - «Одноклассники» (23,4 млн). Если рассматривать видеохостинг YouTube как социальную сеть, то он займет первое место в российском интернете с 41,1 млн пользователей (Три бренда, которым соцсети..., 2016).

Для розничных сетей жизненно необходимы социальные сети, поскольку присутствия в них позволяет привлекать и удерживать аудиторию, общаться с ней, решать проблемы, отвечать на вопросы и негативные комментарии.

Розничные сети также под влиянием факторов научно-технического прогресса включают элементы технологичного маркетинга в программы медиапродвижения: омниканальный маркетинг, геолокационное таргетирование, Wi-Fi сканеры, мессенджеры и другие решения, которые позволяют опередить конкурентов.

Концепция омниканального маркетинга все еще нова и описывается по-разному. Можно предложить следующее определение: организация неразрывного взаимодействия с клиентом через различные каналы: социальные медиа, вебсайт, интернет-магазины, мобильные приложения, колл-центр, офлайн-магазины, е-mail рассылку.

Омниканальность - это, прежде всего, согласованность работы всех каналов коммуникации и влияния на потребителя. Она позволяет контролировать каждый шаг своего клиента, что является очень важным для каждого бизнеса.

Способность корпорации розничного ритейла приспосабливаться к изменениям демографических, культурных, социальных и технических факторов обеспечивает ей способность выживать в условиях рыночных отношений, гармонично развиваться и выстраивать эффективные маркетинговые коммуникации.

Конкурентная борьба на рынке идет постоянно и вследствие трансформации значительного количества рыночных факторов, нет гарантий, что организация, в определенный момент ставшая лидером, будет держать свои позиции долго. Это заставляет различные предприятия развиваться, ведь существует вероятность, что другая фирма окажется более конкурентоспособной. 
Таким образом, внешняя среда по отношению к предприятию, является средой объективной. Способность приспосабливаться к изменениям и предвидеть их влияние на конечные результаты функционирования организации - основное условие в бизнесе. При правильном учете влияния внешнего окружения можно минимизировать непосредственное воздействие на результаты деятельности предприятия и сформировать программу медиапродвижения.

Внутренняя среда представлена факторами, имеющими непосредственное отношение к самой компании и ее возможностям по обслуживанию клиентов. Эту среду образуют поставщики, потребители, компании-конкуренты. Факторы внутренней среды поддаются управленческому воздействию менеджмента компании, позволяя моделировать процессы с целью увеличения прибыли.

К внутренним факторам, непосредственно влияющим на программы медиапродвижения торговых сетей, следует отнести низкий уровень квалификации управленческого персонала, отсутствие эффективной системы управления маркетингом. Внутренние причины зачастую связаны с неправильно выбранной стратегией развития фирмы, ошибками руководства и неопытностью персонала.

\section{СПИСОК ЛИТЕРАТУРЫ}

Гондаренко О.Г. Формирование комплексной маркетинговой стратегии целевого взаимодействия с клиентами: на примере розничных торговых сетей: диссертация кандидата экономических наук: 08.00.05. Ростов-на-Дону, 2013.

Евстигнеева Т.В. (2008) Маркетинг отношений на предприятиях розничной торговли: диссертация кандидата экономических наук: 08.00.05. Ульяновск, 2008.

Мораторий на промо-акции: скидки в магазинах могут запретить (2016), [Электронный ресурс] // URL: https://www.gazeta.ru/business/2020/04/21/13056955 (дата обращения: 25.10.2020).

Ненадлежащая реклама «Ив Роше» (2011), [Электронный ресурc] // URL: https:// www.retail.ru/news/nenadlezhashchaya-reklama-iv-roshe/ (дата обращения: 25.10.2020).

Оборот российского ритейла увеличился на 1,6\% в 2019 году (2020), [Электронный ресурс] // URL: https://new-retail.ru/novosti/retail/oborot_rossiyskogo_riteyla_ uvelichilsya_na_1_6_v_2019_godu9987/ (дата обращения: 25.10.2020).

Оборот российского ритейла в 2020 году снизится на 5,2\% (2020), [Электронный ресурс] // URL: https://new-retail.ru/novosti/retail/oborot_riteyla_v_rossii_v_2020_ godu_snizitsya_na_5_24478/(дата обращения: 25.10.2020).

Реальные доходы россиян в 2019 году продолжили падение (2019), [Электронный ресурс] // URL: https://www.rbc.ru/economics/19/02/2019/5c6c3a0a9a794787 fc457225 (дата обращения: 25.10.2020).

Три бренда, которым соцсети помогли стать лидерами (2016), [Электронный pecypc] // URL: www.retail.ru/cases/tri-brenda-kotorym-sotsseti-pomogli-stat-liderami-/ (дата обращения: 25.10.2020). 
Дёмин Алексей Сергеевич - обучающийся 2 курса образовательной программы магистратуры по направлению подготовки Менеджмент Московского гуманитарного университета. Научный руководитель - доцент, к.э.н. Симакина М.А. Адрес: 111395, Россия, г. Москва, ул. Юности, д. 5. Тел.: +7 (499) 374-58-60. Эл. адрес: kafstat@mosgu.ru

Demin Alexey Sergeevich - Student, Faculty of Economics and Management, Moscow University for the Humanities. Scientific supervisor - docent, Candidate of Economic Sciences Simakina M.A. Postal address: 5, Yunosti St., Moscow, Russian Federation, 111395 Tel.: +7 (499) 374-58-60. E-mail: kafstat@mosgu.ru 